\title{
Direito digital e os obstáculos para o meio judiciário
}

\section{ARTIGO ORIGINAL}

\author{
MACHADO, Daniel Dias ${ }^{1}$
}

MACHADO, Daniel Dias. Direito digital e os obstáculos para o meio judiciário. Revista Científica Multidisciplinar Núcleo do Conhecimento. Ano 06, Ed. 06, Vol. 10, pp. 102-108. Junho de 2021. ISSN: 2448-0959, Link de acesso: https://www.nucleodoconhecimento.com.br/lei/meio-judiciario, DOI: 10.32749/nucleodoconhecimento.com.br/lei/meio-judiciario

\section{RESUMO}

O objetivo do trabalho é analisar o direito digital e os desafios para o universo jurídico. Uma relevante lei é a no 12.965/2014, o Marco Civil da Internet, esta qual firma a execução da Internet no Brasil, contendo nela a previsão de direitos para aqueles que fazem uso da internet e a responsabilidade civil dos que utilizam e dos que provém. O regulamento de delitos virtuais, denominado Lei Carolina Dieckmann (12.737/2012), definiu como delito a ação de penetrar aparelhos tecnológicos transportáveis com objetivo de ter para si, modificar ou excluir dados de um outro sujeito. Além dessa existe a Lei no $13.709 / 2018$, denominada Lei Geral de Proteção de Dados (LGPD), a qual decreta o acesso a informações individuais, com fins de preservar os proprietários e possibilitar que seja feito uso ético e seguro. A Lei 9.854/19 compôs o Plano Nacional de Internet das Coisas (Internet of Things - loT),

\footnotetext{
${ }^{1}$ Tecnólogo em Comércio Exterior pelo Instituto Brasileiro de Gestão Empresarial (IBGEN) de Porto Alegre, Paralegal em Conciliação, Mediação e Arbitragem pela Crown University of Bradenton, Bacharel em Ciências Jurídicas Estrangeiras pela Crown University of Bradenton, Tecnólogo em Serviços Jurídicos e Notariais pelo Instituto Brasileiro de Treinamento (IBF) de Joinville e Bacharel em Psicologia pela Escola Superior Batista do Amazonas (ESBAM). Da mesma forma, completou duas especializações, em Criminologia na Faculdade Famart de Itaúna e em Ética e Justiça na Harvard University em Massachusetts. Possui Mestrado em Administração com Menção em Gestão Organizacional pela Universidad Nacional Experimental de Los Llanos Occidentales Ezequiel Zamora de Santa Bárbara, Doutorado em Ciências Jurídicas pela Crown University de Bradenton e Pósdoutorado em Aplicação da Ontologias para Gestão do Conhecimento pela Crown University de Bradenton na condição de dupla diplomação com o programa de Pós-doutorado em Ontologia do Conhecimento e sua Transcendência da Perspectiva Educacional, e sua aplicação na Gestão Organizacional pela Universidade Fermín Toro de Lara.
} 
determinando premissas importantes para a área indispensável da evolução tecnológica e da mudança digital, objetivando regulamentar e impulsionar a tecnologia no país. Tratou-se de revisão da literatura, baseando-se na busca de artigos publicados entre 2013 e 2020. Os fundamentos de informações utilizadas serão: SCIELO (Scientific Electronic Library Online); google acadêmico.

Palavras-chave: Direito digital, Jurídico, IA.

\section{INTRODUÇÃO}

A prática de direito e tecnologia digital de nosso escritório é formada por uma equipe de profissionais com conhecimento de mercado e experiência em fornecer soluções inovadoras para empresas nacionais e internacionais para os desafios que enfrentam no Brasil.

Uma lei de grande relevância é a Lei no 12.965/2014, popularmente conhecida por "Marco Civil da Internet", a qual estabelece a utilização da Internet no Brasil, apresentando previsão de garantias aos usuários de internet e o dever civil tanto daqueles que usam, quanto daqueles que provêm. A lei dos crimes cibernéticos, conhecida como Lei Carolina Dieckmann (12.737/2012), fez-se ilegal o ato de adentrar aparelhos tecnológicos portáteis com objetivo de conseguir, modificar ou eliminar dados de qualquer terceiro sujeito.

Temos também a Lei ํo 13.709/2018, nomeada como Lei Geral de Proteção de Dados (LGPD), que regulamenta o acesso a dados pessoais para proteger os titulares e permitir que sejam utilizados de forma ética e segura. O decreto 9.854/19 estabeleceu o denominado Plano Nacional de Internet das Coisas (Internet of Things - 107 ), determinando premissas importantes para a área indispensável do desenvolvimento tecnológico e da transformação digital, visando regular e estimular a tecnologia no país.

O objetivo do trabalho é examinar o direito eletrônico e as dificuldades para a esfera jurídica. 
Tratou-se de revisão da literatura, baseando-se na busca de artigos publicados entres 2013 a 2020. As bases de dados utilizadas serão: SCIELO (Scientific Electronic Library Online); Google acadêmico. Os relatores que foram usados para a pesquisa são: Direito eletrônico, judicial, inteligência artificial. Os parâmetros de inserção empregues são: artigos aptos de responder o assunto de método de planejamento, e os padrões de exclusão utilizados são: as revisões de literatura, também os editoriais e por fim os artigos que fossem inaptos para responder o assunto de outros métodos apresentados por este estudo.

\section{DIREITO DIGITAL}

O direito digital é definido como a responsabilidade eletrônica por ações e atos. Em outras palavras, a lei digital se refere ao que você pode ou não pode fazer enquanto usa a Internet. $O$ uso ético abrange todas as atividades na Internet que obedecem às leis da sociedade. $O$ uso antiético abrange todas as atividades na Internet que não cumprem as leis da sociedade. Exemplos de uso ético da Internet incluem citar fontes de maneira adequada, respeitar os outros e ler e cumprir os termos de uso para referências, arquivos, aplicativos etc. que usa (CANEVACCI, 2012).

Exemplos de uso antiético da Internet incluem hacking, pirataria de software, download ilegal de música, plágio, criação e disseminação de vírus. É importante saber que existem consequências significativas para a violação da lei digital (ENGELMANN, 2016).

Independentemente de os alunos conhecerem ou não as leis digitais que regem o uso da tecnologia, eles ainda são responsáveis por suas ações e estão sujeitos à punição por infrações. À medida que o uso da tecnologia digital se torna necessário e comum em nossa sociedade, é importante que os alunos entendam as leis digitais e as consequências de sua violação. A falha em entender e cumprir as leis digitais pode resultar em sérias ramificações legais. Assim, os educadores têm a responsabilidade de garantir que seus alunos estejam informados e prontos para usar a tecnologia digital de maneira legal e ética (KEEN, 2018). 
A lei digital refere-se a requisitos legais, decisões legais e éticas que se relacionam com ambientes digitais. A lei digital pode afetar diretamente os alunos em salas de aula, funcionários e organizações como um todo. Alguns dos desenvolvimentos legais na lei canadense têm se mostrado evolucionários. Como () observam em sua descrição da lei canadense, o Canadá optou por enfatizar e promover a autorregulação em vez de uma legislação extensa. A conscientização e a educação do público têm sido as ferramentas escolhidas para promover a segurança da criança e da família. Os autores observam que a abordagem canadense às referências legislativas pode ser resumida como: "Se é ilegal off-line, é ilegal on-line" (LEVY, 2016).

A transformação digital apresenta desafios complexos para as organizações. Agora, mais do que nunca, os profissionais jurídicos devem ir além do aconselhamento jurídico tradicional e atuar como consultores estratégicos e gestores ativos de risco. A digitalização está transformando as relações legais e contratuais entre empresas, indivíduos e governos. Enquanto isso, a coleta, armazenamento e troca de dados eletrônicos em volumes cada vez maiores não só apresenta novas oportunidades de monetização, mas também apresenta novos riscos e responsabilidades, principalmente nas áreas de privacidade de dados e cibersegurança (PINHEIRO, 2016).

Internet das coisas, robótica e inteligência artificial (IA), blockchain, big data, nuvem e impressão $3 \mathrm{Dz}$ as tecnologias estão evoluindo rapidamente e, como resultado, organizações grandes e pequenas, privadas e públicas, estão repensando fundamentalmente como funcionam. Isso é verdade para todos os nossos clientes que operam na produção, varejo, e-commerce, logística, indústria automotiva, tecnologia da informação, FMCG, mídia e outros setores (RONDE, 2017).

Legislação regulatória digital, incluindo a identificação de áreas de risco e desenvolvimento de planos para enfrentar os desafios da mudança transformadora, abrangendo os aspectos legais da regulação em termos de transformação digital, assessoria de compliance em Inteligência Artificial, tecnologias VR / AR, impressão 
3D e robótica (RPA), criptomoedas e blockchain, e aconselhamento sobre conformidade legal com regulamentos específicos de IT / TMT (BALLY, 2017).

Comércio eletrônico, incluindo consultoria sobre requisitos regulatórios para comércio eletrônico e privacidade de dados, conformidade com as leis de proteção ao consumidor e concorrência, criação de estruturas legais para negócios de comércio eletrônico, elaboração e análise de contratos eletrônicos (termos de uso, consentimentos, computação em nuvem acordos: SaaS, PaaS, laaS, etc.), promoção de bens e serviços online, programas de fidelidade / incentivo para contratantes e consumidores, contratação de TI, contratos inteligentes e assinaturas eletrônicas (BITTAR, 2018).

Internet of Things (loT)/ Connected Products / Home Connect, incluindo recomendações sobre conformidade com requisitos globais de privacidade de dados para empresas digitais, privacidade por padrão e design em desenvolvimento de produto digital, conformidade de computação em nuvem, proteção de dados para plataformas online e aplicativos móveis, e estruturas para transferência internacional de dados (CANEVACCI, 2012).

\section{CONCLUSÃO}

A legislação digital deve ser distribuída de maneira muito mais eficaz e equitativa. É provável que seja colorido, melodioso, até barulhento e capaz de movimento e interação (ou seja, totalmente comunicativo). Pode ser caracterizado por agências administrativas mais horizontais, com menos controle de cima para baixo, atraso e rigidez, mas maior consistência. E, finalmente, deve oferecer mais oportunidade e maior influência para aqueles que trabalham em Inteligência Artificial e Direito.

À medida que os dados legais digitalizados proliferam, há uma necessidade cada vez maior de agentes inteligentes para organizá-los (e filtrá-los) em nome do usuário. Como alguns pintariam o cenário futuro, todos teremos agentes de software conscientes de nossas necessidades contínuas de informações, colhendo novos 
materiais de importância para nós e prontos para se aventurar em nossa licitação para adquirir informações pertinentes a uma necessidade emergente. Mas um futuro mais plausível, certamente aquele para o qual há grande demanda hoje, é para o agente do agente (ferramentas que servem a autores, editores, advogados ou juízes).

\section{REFERÊNCIAS}

BALLY, Romain, de nouveaux droits pour um nouveau Droit, in Numérique: nouveaux droits, nouveaux usages; actes de Colloque (CHATRY, Sylvain; GOBERT, Thierry), 2017.

BITTAR, Eduardo C. B. Introdução ao estudo do direito: humanismo, democracia e justiça. São Paulo: Saraiva, 2018.

CANEVACCI, Massimo. Corpos polifônicos e tecnologias digitais, in 0 triunfo do corpo: polêmicas contemporâneas (COUTO, Edvaldo Souza; GOELLNER, Silvana Vilodre, orgs.), Rio de Janeiro, Vozes, 2012, ps. 33-64.

ENGELMANN, Wilson, 0 direito em face das Nanotecnologias: novos desafios para a Teoria Jurídica no século $\mathbf{X X I}$, in os novos direitos no Brasil: natureza e perspectivas - uma visão básica das novas conflituosidades jurídicas (WOLKMER, Antonio Carlos; LEITE, José Rubens Morato, orgs.), 3.ed., 2016, ps. 435-460.

KEEN, Andrew, Inteligência artificial vai mudar todos os relacionamentos humanos, in Folha de São Paulo, Entrevista a Silas Martí, Segunda-Feira, 05 de março de 2018, A 10.

LÉVY, Pierre. As tecnologias da inteligência: o futuro do pensamento na era da informática. 2.ed. Tradução de Carlos Irineu da Costa. São Paulo: Editora 34, 2016.

PINHEIRO, Patrícia Peck, O Direito Digital como paradigma de uma nova era, in Os novos direitos no Brasil: natureza e perspectivas - uma visão básica das 
novas conflituosidades jurídicas (WOLKMER, Antônio Carlos; LEITE, José Rubens Morato, orgs.), 3.ed., 2016, ps. 401-433.

RONDE, François Rossignol de la. Droit des Technologies avancées. Tome 1. Libertés, Données et Fichiers. Bruxelles: La Charte, 2017.

Enviado: Maio, 2021.

Aprovado: Junho, 2021. 